Correction

\title{
Correction: A No Reference Image Quality Assessment Metric Based on Visual Perception. Algorithms 2016, 9, 87
}

\section{Yan Fu and Shengchun Wang *}

College of Computer Science and Technology, Xi'an University of Science and Technology, Xi'an 710054, China; fuy@xust.edu.cn

* Correspondence: wangshengchun1991@163.com; Tel.: +86-29-8558-3173

Academic Editor: Henning Fernau

Received: 19 May 2017; Accepted: 25 May 2017; Published: 26 May 2017

We would like to make the following change to our article [1]. The sub-graph (c) DIIVINE was not edited correctly in the original Figure 13. The figure should be replaced with:

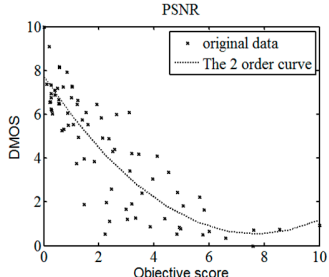

(a) PSNR

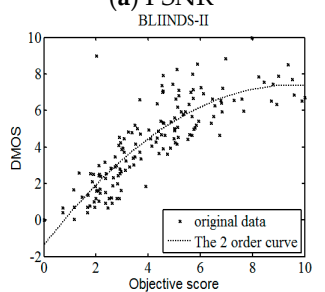

(d) BLIINDS-II

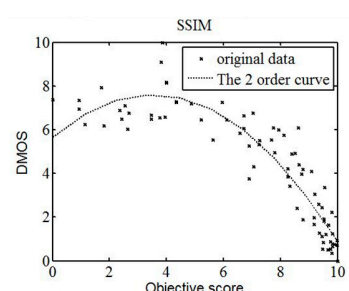

(b) SSIM

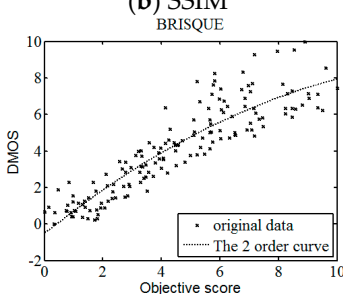

(e) BRISQUE

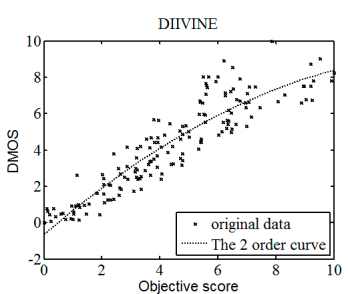

(c) DIIVINE

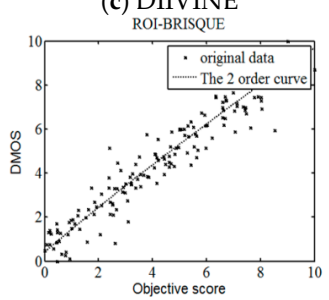

(f) Method of this paper

Figure 13. Scatter plots of DMOS versus different model predictions. Each sample point represents one test image in the entire LIVE database. (a) PSNR model; (b) SSIM model; (c) DIIVINE model; (d) BLIINDS-II model; (e) BRISQUE model; (f) Model of this paper (ROI-BRISQUE).

We apologize for any inconvenience this may cause. The change does not affect the scientific results. The manuscript will be updated and the original will remain online on the article webpage.

\section{References}

1. Fu, Y.; Wang, S. A No Reference Image Quality Assessment Metric Based on Visual Perception. Algorithms 2016, 9, 87. [CrossRef]

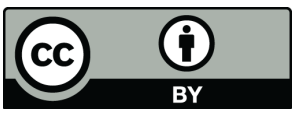

(C) 2017 by the authors. Licensee MDPI, Basel, Switzerland. This article is an open access article distributed under the terms and conditions of the Creative Commons Attribution (CC BY) license (http:/ / creativecommons.org/licenses/by/4.0/). 